\title{
Study on Ultrasound Welding Process of Aluminum/Copper Dissimilar Metals
}

Man Tang ${ }^{1,2}$, Peilei Zhang ${ }^{1,21} *$,Zhishui $\mathrm{Yu}^{1,2}$, Haichuan Shi ${ }^{1,2}$, Shaowei $\mathrm{Li}^{1,2}$, Di Wu ${ }^{1,2}$, Hua

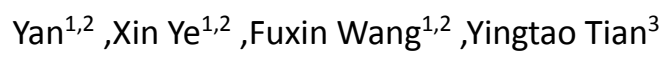

1. School of Materials Engineering, Shanghai University of Engineering Science, Shanghai

201620, China

2. Shanghai Collaborative Innovation Center of Laser Advanced Manufacturing Technology,

Shanghai 201620, China

3. Department of Engineering, Lancaster University, Bailrigg, Lancaster, LA1 4YW, United

Kingdom

\begin{abstract}
Aluminum/Copper dissimilar joints are widely used in electronics, automobile industry and battery manufacturing. Ultrasonic spot welding (USW), as a quality, efficient, clean and low-consumption solid phase bonding (SPB) technology, is applicable for the connections of aluminum/copper and other highly conductive and heat-conducting materials. At present, this technique has been concerned by automobile producers and lithium battery manufacturers at home and aboard. In this work, the optimal performance of the ultrasonic welding process of aluminum/copper dissimilar joints is studied. Through a single-factor test on how welding parameters (lap mode, welding pressure, welding amplitude and welding energy) influence on the quality of welding joints, it has found that the lap mode of aluminum plates on the top and copper plates on the bottom $(\mathrm{Al} / \mathrm{Cu})$ is better than that of copper plates on the top and aluminum plates on the bottom $(\mathrm{Cu} / \mathrm{Al})$, under the optimal parameters (40Psi, $45 \mu \mathrm{m}$ and $500 \mathrm{~J})$.
\end{abstract}

* Corresponding author at: Room 3109, School of Materials Engineering, 333 Long Teng Rd. Songjiang Campus of Shanghai University of Engineering Science, Shanghai, 201620, China. Tel: +86 21 67761412; Fax: +86 21 67791377. Email addresses: peilei@ sues.edu.cn (Peilei Zhang). 
Under this group of parameters, the $\mathrm{Al} / \mathrm{Cu}$ joint can form a cladding mechanical occlusion. The element diffusion layer is $2 \mu \mathrm{m}$ and the maximum failure load of the joint specimen is $605 \mathrm{~N}$. Besides, the results show that when the welding energy is at a lower level, the unconnected area on the interface will be larger which brings a higher welding quality; However, when the welding energy is too much, the quality will decrease gradually due to the softening effect of the material.

Key words: ultrasonic spot welding; Aluminum/Copper dissimilar metals; ultrathin $\mathrm{Al} / \mathrm{Cu}$

\section{Introduction}

In order to protect the environment and save energy, many countries have issued policies to promote new energy vehicles to replace fuel vehicles. The new energy automobile has been greatly developed, but there are still problems in low endurance mileage and energy efficiency [1]. Among the problems, the top priority is energy density, energy storage efficiency and reliability of battery module [2]. Therefore, the power battery plays a vital role in the manufacturing of new energy automobiles. At present, the new-energy battery pack is connected through a mass of cells which are made up of shell, electrolyte, diaphragm and metals with two different potential (PD) differences[3-4]. For lithium batteries with high-energy density, the battery lug is usually composed of aluminum and copper. There are various types of Busbar materials that are used for connecting electrodes, such as aluminum, copper and nickel-plated copper. Thus materials of different thickness and heterogeneous materials should be connected reliably and efficiently in the process of battery manufacturing. [5-6].As there are quite different physical and chemical properties between aluminum and copper (such as thermal conductivity, thermal expansion coefficient and melting point), it is difficult to achieve an effective welding with traditional welding methods. Besides, an interface layer is formed at the joint of aluminum-copper welded joints owing to the limited mutual solubility between aluminum and copper at room temperature. This will lead to Brittle intermetallic compounds. As a result, the strength and plasticity of the welded joint are reduced and easily causes cracks[7-9]. Abbasi et al. [10] found that the thickness of aluminum-copper intermetallics has a certain critical value on the strength and ductility of the joint; and the joint with a comprehensive performance less than $2.5 \mu \mathrm{m}$ shows an excellent comprehensive property. When connected as a circuit element, the conductivity decreases and the resistance of the aluminum-copper intermetallic compound is 8 times that of the base metal [11]. The ultrasonic metal welding is first introduced in early 1950s for wire bonding, tube sealing, and thin metal foils joining[12]. This technique uses relatively less energy as compared to conventional resistance spot welding (RSW). In USW, bonding is normally achieved at relatively low temperatures $\left(\sim 300{ }^{\circ} \mathrm{C}\right)$ in short weld cycles (typically $<0.5 \mathrm{~s}$ ) [13].Ultrasound metal welding is a high-quality, efficient, low-consumption and clean solid phase bonding (SPB) technology. It is suitable for the connection of high 
conductivity and thermal conductivity materials like $\mathrm{Al} / \mathrm{Cu}$, which has attracted the attention of automobile producers and lithium battery manufacturers at home and abroad. However, influenced by material properties $(\mathrm{Al} / \mathrm{Cu} / \mathrm{Ni}$, etc.) and material thickness $(10 \mu \mathrm{m}-1 \mathrm{~mm})$, the friction heat generated and plastic deformation during welding is not clear. It causes problems including poor quality consistency of ultrasonic welded joints and a small selection range of process parameters.

By means of ultrasonic spot welding of $0.2 \mathrm{~mm} \mathrm{~T} 2 \mathrm{Cu}$ and $1060 \mathrm{Al}$ alloy foil, the macroscopic weld formation and features of micro-structures under different welding parameter combination and lap joints are studied and its formation mechanism is revealed in this paper.

\section{Experimental procedures}

\subsection{Materials}

Typical lithium-ion batteries adopt $\mathrm{Cu}$ and $\mathrm{Al}$ as electrodes. The welding base metal used in this experiment is $1060 \mathrm{Al}$ alloy and T2 $\mathrm{Cu}$. The length, width and thickness of base metal are $100 \mathrm{~mm}, 50 \mathrm{~mm}$ and $0.2 \mathrm{~mm}$ respectively. The compositions of $1060 \mathrm{Al}$ Alloy and T2 Cu are shown in Tables 2-1 and 2-2. $1060 \mathrm{Al}$ alloy belongs to industrial pure Al. Under room temperature, the microstructure of $1060 \mathrm{Al}$ alloy is shown in Fig. 2-1(a). T2 $\mathrm{Cu}$ has good electrical conductivity, thermal conductivity, corrosion resistance and processing performance, which is often used in power-related equipment. At normal temperature, the microstructure of $\mathrm{T} 2 \mathrm{Cu}$ is shown in Fig. 2-1(b).

Table 1-1 Comparison between the physical properties

\begin{tabular}{ccc}
\hline Physical Properties & $\mathrm{Cu}$ & $\mathrm{Al}$ \\
\hline Density & $8.9 \mathrm{~g} / \mathrm{cm} 3$ & $2.71 \mathrm{~g} / \mathrm{cm} 3$ \\
Fusion point & $1083{ }^{\circ} \mathrm{C}$ & $660{ }^{\circ} \mathrm{C}$ \\
Thermal conductivity & $390 \mathrm{~W} / \mathrm{mK}$ & $226 \mathrm{~W} / \mathrm{mK}$ \\
coefficient & & \\
Thermal expansivity & $17 /{ }^{\circ} \mathrm{C} .10^{6}$ & $24 /{ }^{\circ} \mathrm{C} .10^{6}$ \\
\hline
\end{tabular}


Table 2-1 Chemical element composition of 1060 aluminum/\%

\begin{tabular}{cccccccc}
\hline Al & Fe & Mn & Si & Zn & Ti & Cu & Mg \\
\hline 99.6 & 0.35 & 0.03 & 0.25 & 0.05 & 0.03 & 0.05 & 0.03 \\
\hline
\end{tabular}

Table 2-2 Chemical element composition of T2 copper/\%

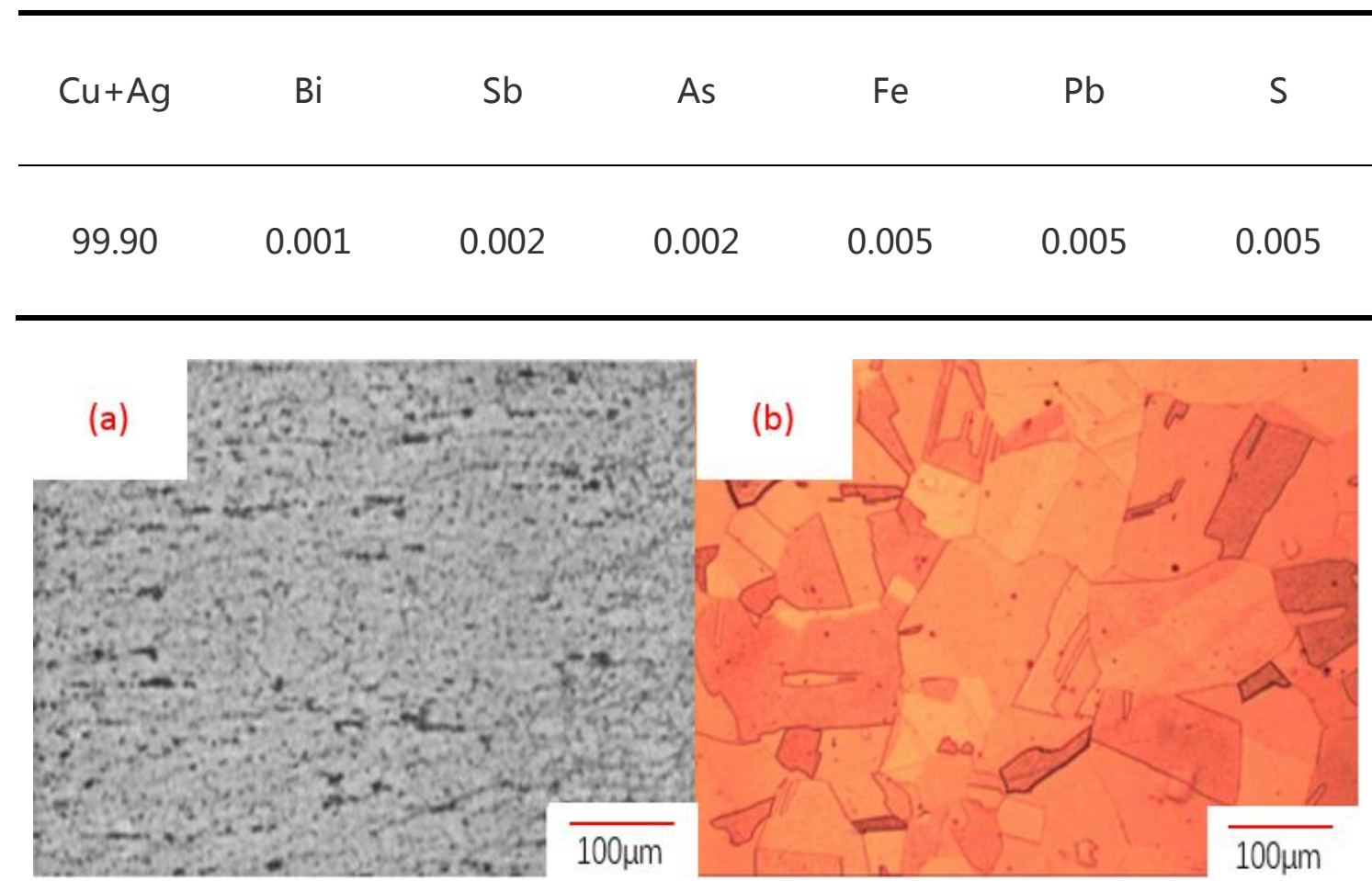

4Fig.2-1 Microstructure of base metal. (a) Microstructure of $1060 \mathrm{Al}$; (b) Microstructure of $\mathrm{T} 2 \mathrm{Cu}$ 


\subsection{Experimental equipment and methods}

Ultrasound spot welding machine ULTRAWELD L20 produced by Branson Ultrasonics (Shanghai) Company is selected in the experiment. The experimental equipment is shown in Fig. 2-2.
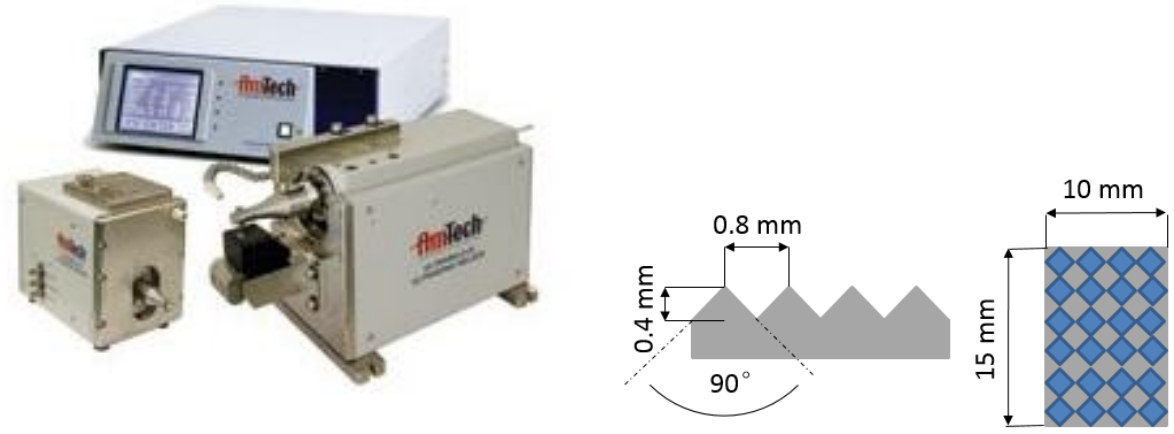

Fig.2-2 (a) ULTRAWELD L20 Ultrasonic spot welder Fig.2-2 (b) The welding head

$$
\text { size }
$$

The sheets provided are machined into specifications of $100 \mathrm{~mm}$ in length, $50 \mathrm{~mm}$ in width and 0.2mm in thickness, as shown in Fig. 2-3 (a). Before the ultrasonic welding process, the board is polished with 2000-grid sandpaper and then cleaned with alcohol. For lap configurations that may simulate actual lithium-ion battery welding applications, two different lap configurations are used, as shown in Fig. 2-3 (b) and Fig. 2-3 (c).

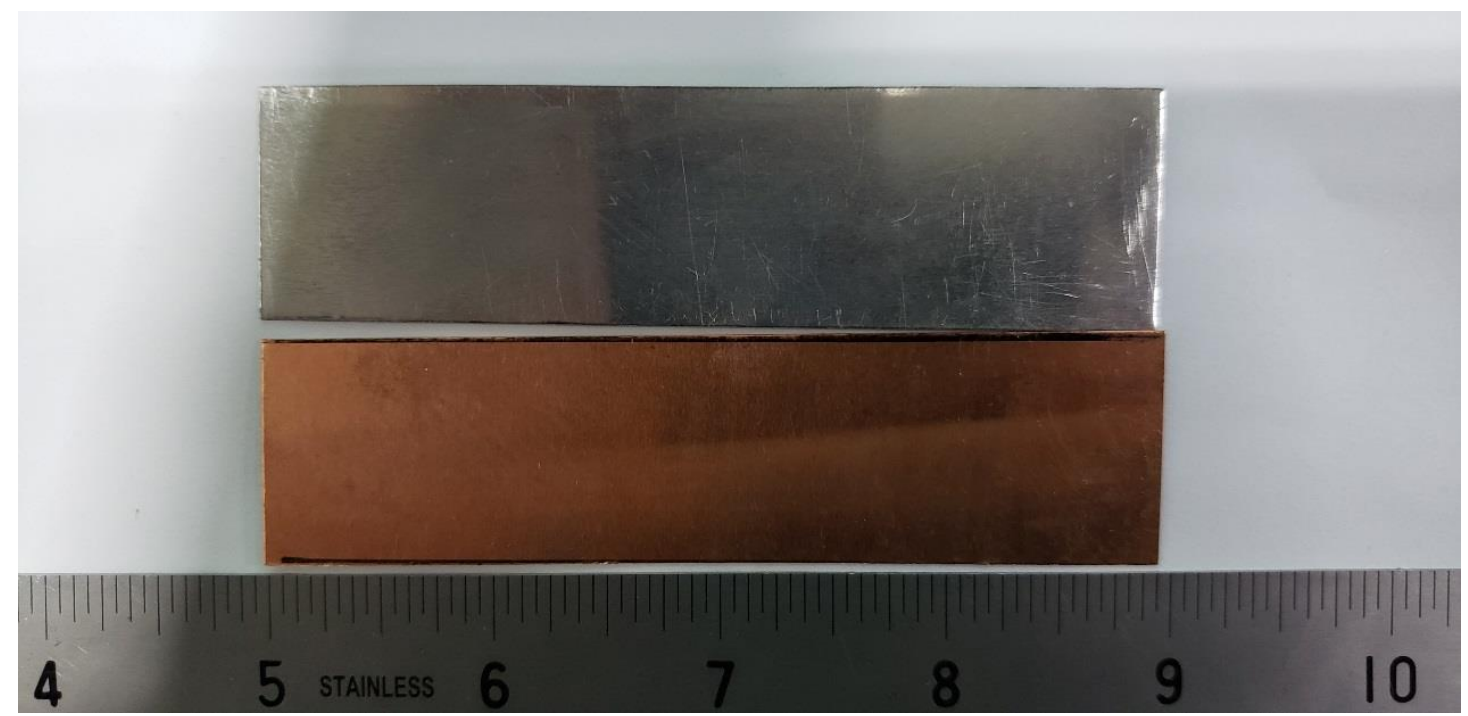

Fig.2-3 ( a ) Schematic of model object 


\section{$\mathrm{Cu}$}

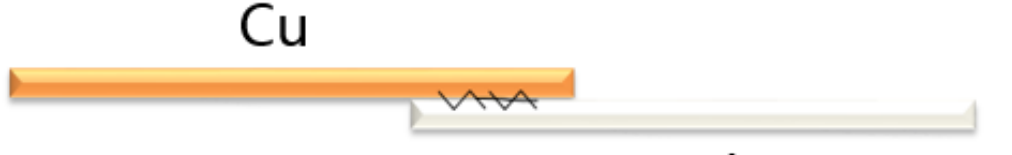

Al

Fig.2-3 ( $b$ ) Configurations of Cu/Al joints for the UW process

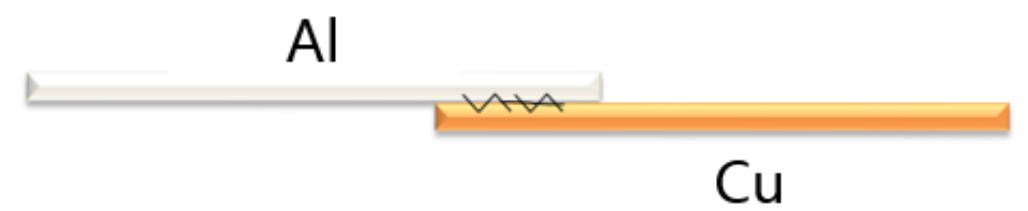

Fig.2-3 ( c ) Configurations of $\mathrm{Al} / \mathrm{Cu}$ joints for the UW process

The welding parameters and levels used in the experiment are shown in Table 2-3 and Table 2-4. The welding quality is evaluated according to the maximum tensile load of the joint. Three repetitive tests are carried out under each group of welding parameters; and the effects of each parameter on the quality of welded joints are studied by singlefactor test method.

Table 2-3 Cu/Al Welding parameters

\begin{tabular}{cccc}
\hline Cu/Al & Welding pressure ( Psi ) & Welding energy $(\mathrm{J})$ & Welding amplitude $(\mu \mathrm{m})$ \\
& 40 & 400 & 32 \\
\hline The sample 1 & 40 & 400 & 37 \\
\hline The sample 2 & 40 & 450 & 37 \\
\hline The sample 3 & & \\
\hline
\end{tabular}


Table 2-4 Al / Cu Welding parameters

\begin{tabular}{cccc}
\hline $\mathrm{Al} / \mathrm{Cu}$ & Welding pressure ( Psi ) & Welding energy $(\mathrm{J})$ & Welding amplitude $(\mu \mathrm{m})$ \\
\hline The sample 1 & 40 & 400 & 32 \\
\hline The sample 2 & 40 & 400 & 37 \\
\hline The sample 3 & 40 & 450 & 37 \\
\hline
\end{tabular}

A universal testing machine (ZXICK) is used to test the maximum tensile load of dissimilar Al-Cu joints. The loading speed is $5 \mathrm{~mm} / \mathrm{min}$. KEYSIGHT-G200 nanomicrohardness tester is used to test the microhardness. The load duration is $15 \mathrm{~s}$ and the load size is $10 \mathrm{mN}$.

After ultrasonic welding, the samples are cut by wire cutting, and the transverse sections are grinded and polished in turn. The interface morphology and atomic diffusion of welded joints are studied through scanning electron microscope with VHX-5000 digital microscope and TESCAN VEGA3 .

\section{Results and discussions}

\subsection{Evaluation of mechanical joint performance}

The welding pressure acts on the surface of the welded parts through the welding joint, and generates positive pressure at the interface of the welded parts. The shear friction force is produced by the relative sliding of the upper part and the lower part in the welding process, which directly affects the friction heat and plastic deformation of the part interface [14]. This is very important for the quality of welded joints. Different process parameters have great influence on welding. If the welding parameters are not suitable, there will be bonding between the welding head and the part or virtual welding of the joint. Virtual welding and joint bonding are not allowed. For $\mathrm{Cu} / \mathrm{Al}$ welding (Fig. $3-1$ ), the welding amplitude is $32-37 \mu \mathrm{m}$. When the welding pressure is $40 \mathrm{Psi}$ and the welding energy is $400 \mathrm{~J}-450 \mathrm{~J}$, the joint shows a good quality and the effective welding spot can be obtained. When the welding pressure is 40Psi, the welding energy is $400 \mathrm{~J}$ and the welding amplitude is $32 \mu \mathrm{m}$, the maximum failure load of the joint specimen is 463.48N. Al/Cu welding (Fig. 3-1) has a welding amplitude of 32-37 $\mu \mathrm{m}$. When the welding pressure is $40 \mathrm{Psi}$ and the welding energy is $400 \mathrm{~J}-450 \mathrm{~J}$, the joint quality is good and the effective welding joint can be obtained. When the welding pressure is 40Psi, 
the welding energy is $450 \mathrm{~J}$ and the welding amplitude is $37 \mu \mathrm{m}$, the maximum failure load of the joint specimen is $605 \mathrm{~N}$. It proves that for $0.2 \mathrm{~mm}$ aluminum-copper welding, only suitable welding parameters can get good quality joints.

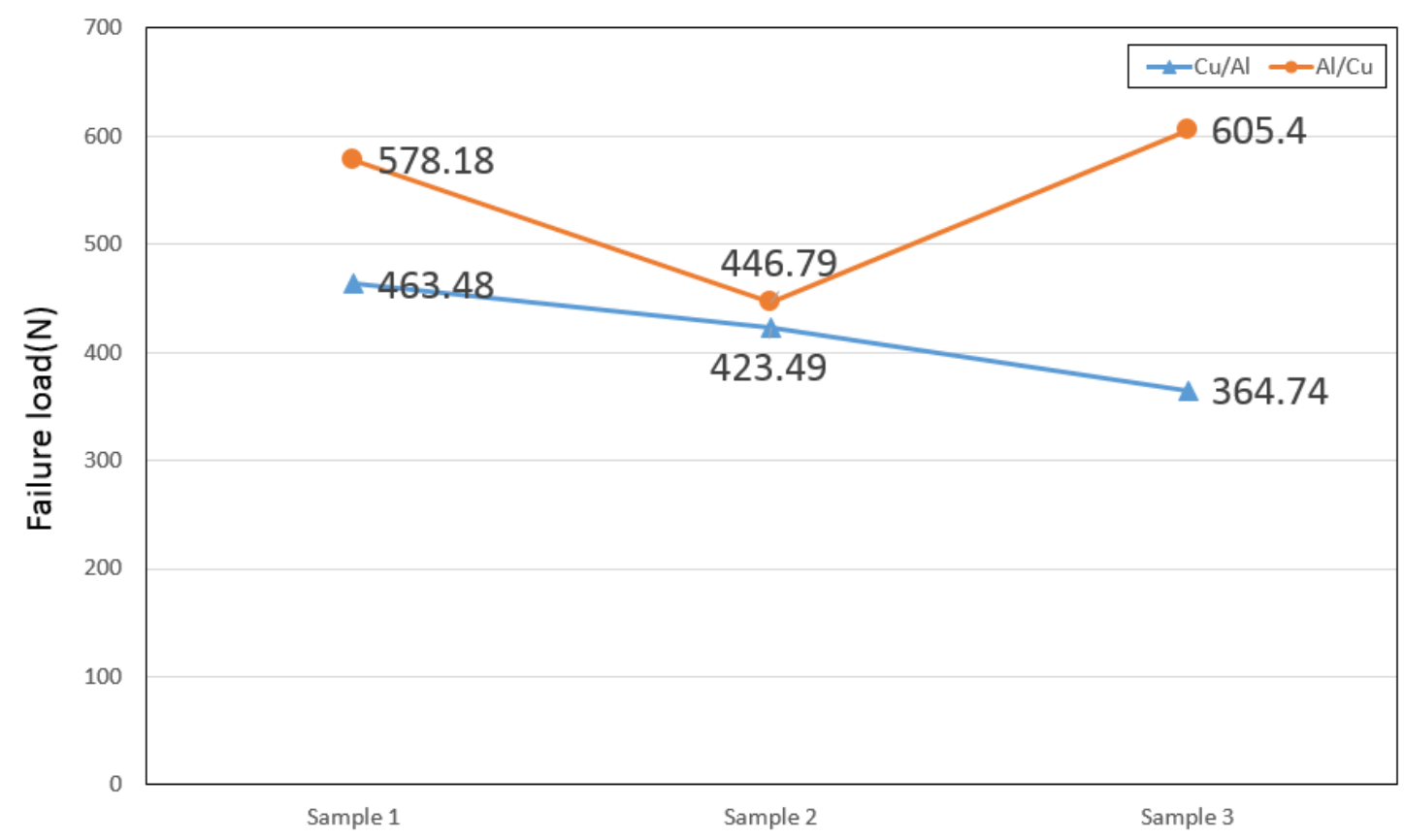

Fig. 3-1 Diagram of Cu-Al and Al-Cu lap specimen

\subsection{Fracture morphology}

In order to further understand the welding characteristics of the welding interface under different parameters, the fracture morphology after the tensile test was studied. Although there are no standard guidelines for the evaluation of weld quality in the UW process, the common practice is performed by actual weld nugget size assessment, which is usually obtained by the peel test, according to Hu et al.1996.In an effort to further understand the welding features of the welding interface under different parameters, the fracture morphology after the tensile test is studied. Although there are no standard guidelines for the evaluation of weld quality in the UW process, the common practice is performed by actual weld nugget size assessment, which is usually obtained by the peel test, according to $\mathrm{Hu}$ et al[15]. As shown in Fig. 3-2, most of the fracture occurs on the $\mathrm{Al}$ side, which is due to the large plastic deformation of $\mathrm{Al}$ in ultrasonic welding; and the strength itself is inferior to that of copper. The fracture occurs at the edge of the weld, not at the center of the weld, which indicates that the bonding strength of the interface between the center of the aluminum-copper welding is higher than that of the edge of the weld.Fig. 3-2-a, Fig. 3-2-b and Fig. 3-2-c are Cu/Al lap joints. Effective solder joints are formed at the joints. Fig. 3-2-d, Fig. 3-2-e and Fig. 3-2-f are $\mathrm{Al} / \mathrm{Cu}$ laps. Effective solder joints can be observed not only at the weld joints, but also around the solder joints, gray-white aluminum layer can be observed. The best bonding strength of aluminum-copper pattern 3 is shown in Fig. 3-2-f. A continuous 
and stable aluminum layer without notches is formed on the copper side of the fracture. This indicates that plastic deformation and material softening occur in the aluminum side under ultrasonic welding, but the material flow is more uniform to fill the gap between aluminum and copper because of reasonable parameters. The welding results are better, and the parameters of aluminum/copper Sample 3 are the optimum parameters. The best combination of plastic deformation, material softening and material flow is achieved under the parameters of $\mathrm{Al} / \mathrm{Cu}$ Sample 3. It accords with the explanation of mechanical properties of six groups of aluminum-copper welding. Energy Dispersive Spectroscopy (EDS) surface scanning is carried out on the fracture of $\mathrm{Al} / \mathrm{Cu}$ sample 3. As shown in Fig. 3-3, in Fig. 3-3-b, it can be found that the distribution of green aluminum and red copper elements is uniform and stable. In Fig. 3-3-c, it can be seen that the distribution of aluminum element on copper near the solder joint is uniform and continuous, and there is no gap. It is shown that the continuous aluminum layer only on the Al/Cu Sample 3 increases the effective link length of the ultrasonic welding of aluminum and copper and enhances the welding strength benefiting from the uniform flow of the material on the copper side.
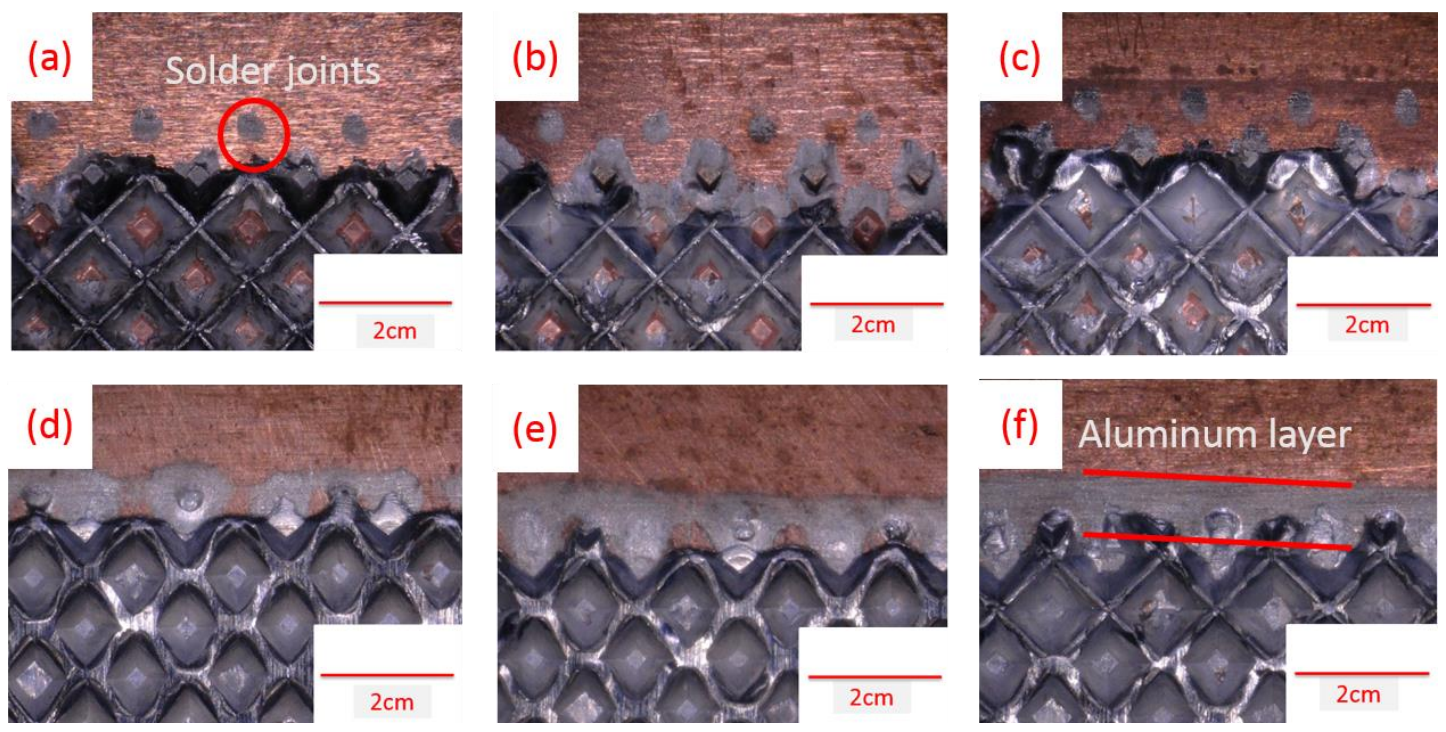

Fig. 3-2 fracture of Al-Cu lap specimen 

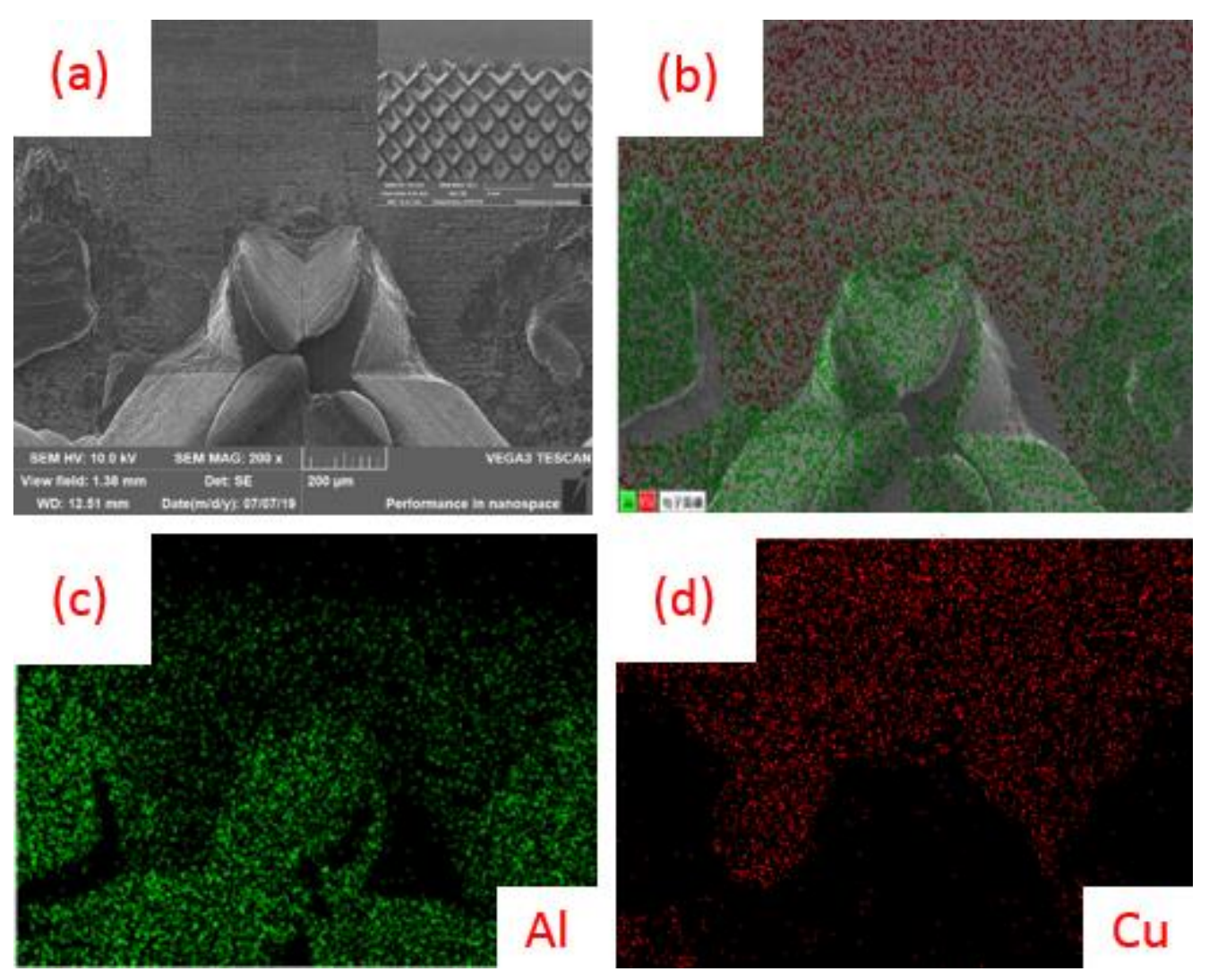

Fig. 3-3 Al/Cu sample 3 Fracture EDS
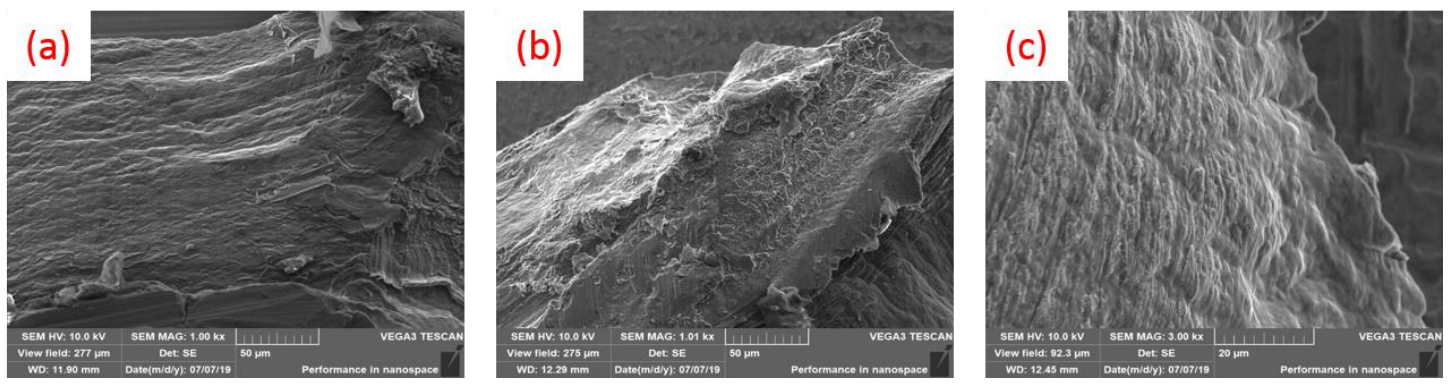

Fig. 3-4 Fracture SEM of Al-Cu Pattern

The fracture morphology of aluminum-copper lap joint is shown in Fig. 3-4. Fractures occur on the Al side. A cluster of cleavage steps parallel to each other and located at different heights can be clearly found on the graph. It can be judged that the fracture belongs to brittle fracture. The fracture occurs at the edge of the weld, not at the center of the weld, which indicates that the bonding strength of the interface between the center of the Al-Cu welding is higher than that of the edge of the weld.

\subsection{Surface images of weld parts}




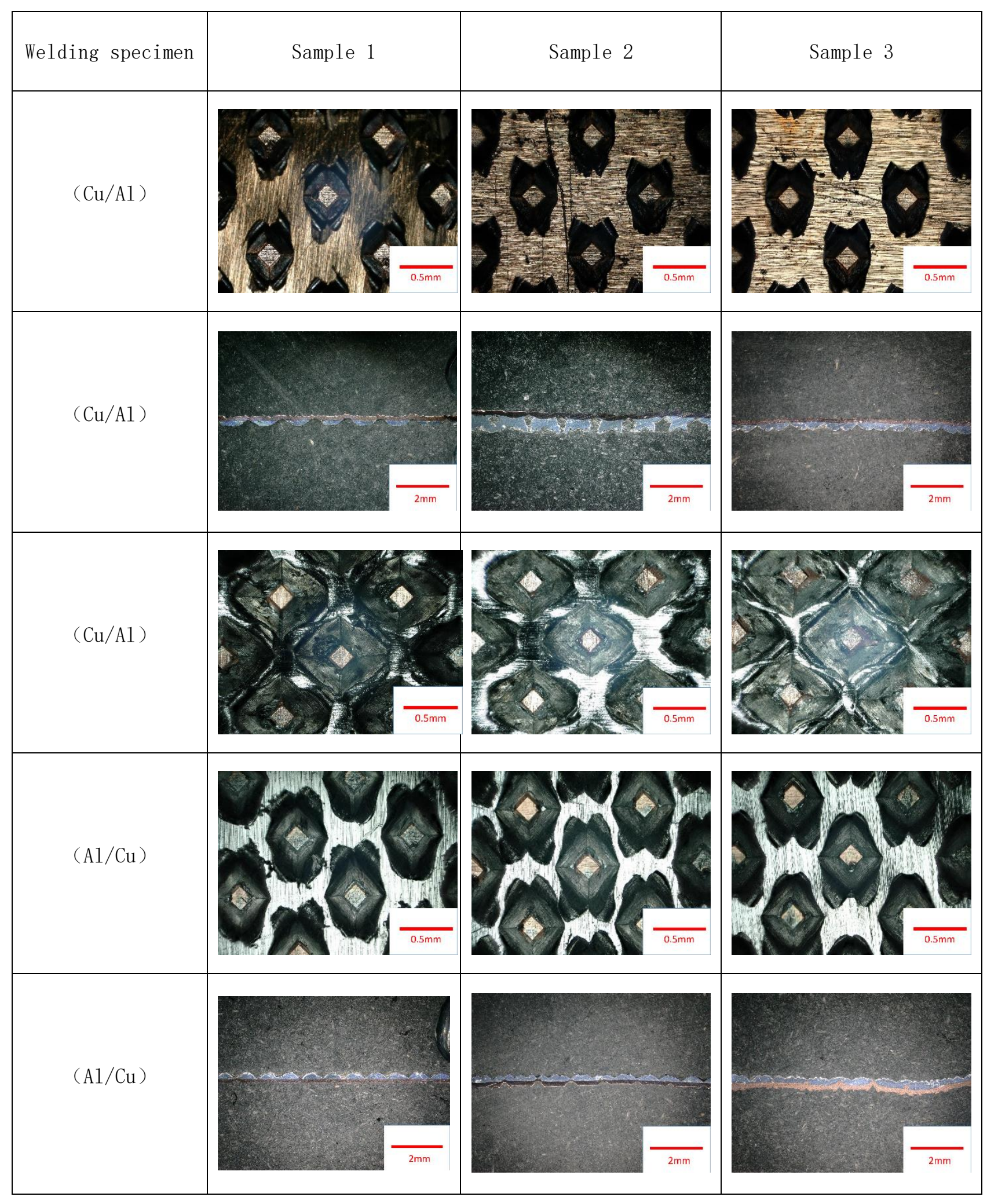




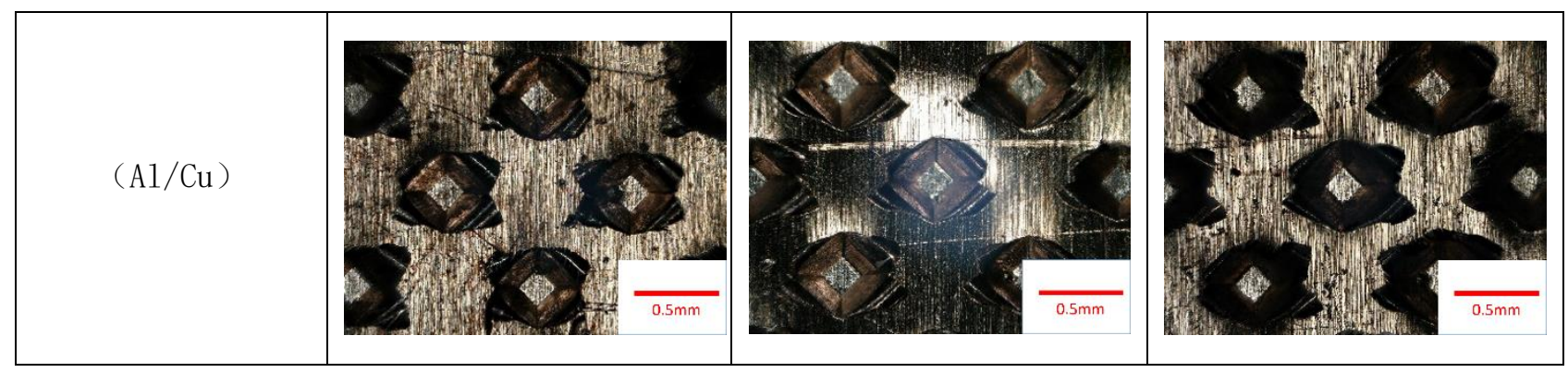

Fig. 3-5 Surface and Metallogram of Copper-Aluminum Overlap Specimens

As welding energy and amplitude increase, the indentation of ultrasonic probe and anvil die is more obvious. Under clamping force of 40psi and welding energy of $400 \mathrm{~J}$, the indentation further increases and the material deforms greater as the welding amplitude rose from $32 \mu \mathrm{m}$ to $37 \mu \mathrm{m}$. Even so, the material deformation will decrease when the amplitude gradually gets stronger. This indentation change can be explained as follows: the initial deep indentation is because there is sufficient space that can accommodates the flow of deformed material. However, with the increase of welding amplitude, material flow decreases because there is no more space to accommodate material flow. In the USW process, material flow is caused by extensive plastic deformation, which improves the clamping force of the specimen and the friction work along the weld interface. Excessive material flow leads to the thinning and softening of materials, which has a negative impact on welding strength [16].

As shown in Fig. 3-5, the prominent small ear shape deformation at the contact of the welded joint is the strong plastic deformation on both sides of the aluminum and copper during welding. The plastic deformation of copper sheet at the welding interface is larger than that of copper sheet at the aluminum side. The mechanical occlusion formed by the welding of aluminum and copper at the interface changes from the original mutual occlusion of aluminum and copper to the interlacing and occlusion of each other. This kind of mechanical occlusion not only benefits the bonding quality of the interface, but also further promotes the diffusion and bonding of metal atoms, thereby improving the quality of the joint [17].This prominent island shape represents the mechanical occlusion between aluminum and copper, but the size of the island varies, indicating that the mechanical occlusion effect of aluminum-copper interface varies. Ultrasound welding exerts horizontal vibration friction force and vertical clamping force to the weldment through the sharp teeth on the electrode. On the one hand, extruding the material from the surface to the interface produces volume effect, which leads to severe plastic deformation of aluminum in the process of ultrasonic welding, and makes the bonding between aluminum and copper more closely, which is conducive to metal bonding. On the other hand, severe plastic deformation and highfrequency ultrasonic vibration friction make the $\mathrm{Al}_{2} \mathrm{O}_{3}$ oxide film break down and fall off, so that pure aluminum-copper metals can be close to each other and form metal bonding connection. The plastic deformation interface of aluminum side is better than that of copper side. It can be summarized as follows. First of all, the hardness of copper is higher than that of aluminum, and continuous contact wear and welding interface deformation occur. Therefore, the softened aluminum sheet has more and deeper holes, 
which can penetrate the aluminum side. Next the heat generation appears in the mutual abrasion of the contact surfaces and shear deformation, which mostly remain in the aluminum side. This is due to that the thermal conductivity $(390 \mathrm{~W} / \mathrm{mk})$ of copper is higher than that of aluminum ( $226 \mathrm{~W} / \mathrm{mk})$ as reported in a review by Fujii et al. (2016) [18], resulting in softening the aluminum side. Therefore, the plastic deformation of the aluminum side is greater than that of the $\mathrm{Cu}$ side.
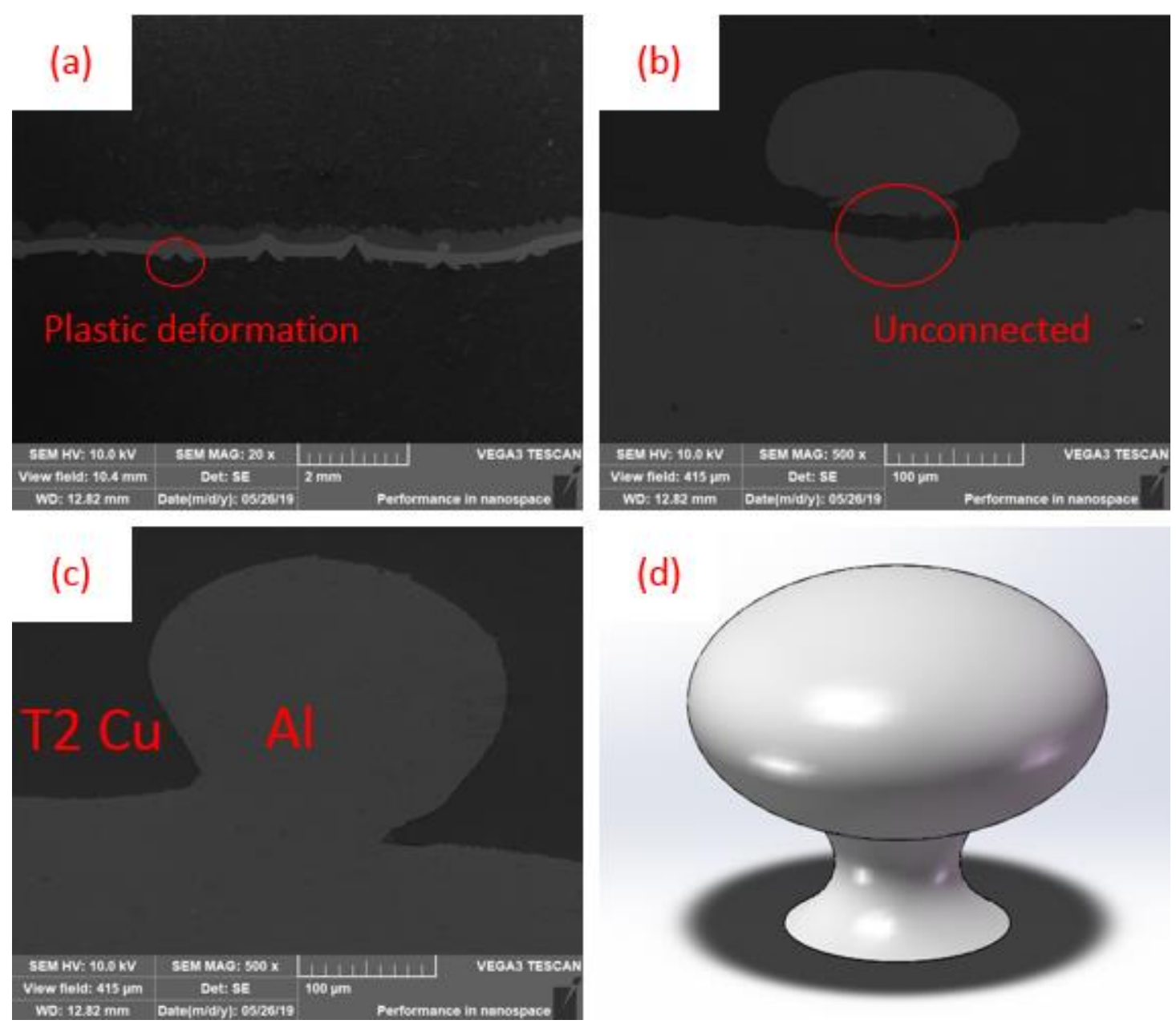

Fig.3-6 Al-Cu lap sample 3 SEM and island embedding diagram

Excellent mechanical occlusion can make the $\mathrm{Al} / \mathrm{Cu}$ lap more tightly. As shown in Fig.3-6-a, there is a large mechanical occlusion which does not appear in other patterns. This is due to the large plastic deformation on both sides of the aluminum and copper welded joints under the parameters of sample 3. The plastic deformation of $\mathrm{Al}$ side is more severe. In addition to the obvious small ear like protrusion on the outer side of the welding head, aluminum is also driven into the inner part of the copper layer on the inner side of the welding head. Inside the copper layer, an island-like insertion is formed, which increases the effective link area between aluminum and copper. Island-like barbed links also make ultrasonic welding of aluminum and copper more compact. Fig. 3-6-b and 3-6-c are island-shaped chimeras connected with copper layer respectively. There are connected and unconnected observation maps, which are caused by different 
observation positions of ultrasonic welding. From these two pictures, we can clearly judge that the plastic deformation and material flow caused by the vibration and friction force of ultrasonic welding are beneficial to the formation of "big head" islands connected by $\mathrm{Al}$ and $\mathrm{Cu}$. The upper end of the island embedded in the copper layer is larger and the lower end is narrower, similar to a human head. The effective linking area of the lower narrow part of the copper layer is increased, which strengthens the connection between $\mathrm{Al}$ and $\mathrm{Cu}$. The optimal results of ultrasonic welding of ultra-thin $\mathrm{Al}$ and $\mathrm{Cu}$ are obtained. This is also the reason why the failure load of sample 3 is the highest.

\section{4 influence of metal atom diffusion and plastic deformation}

Under the action of ultrasonic vibration and clamping pressure, the metal surface contacts closely. It can produce more heat, promoting the rise of temperature and the softening of materials. Therefore, severe plastic deformation can occur at the welding interface. In ultrasonic metal welding, the plastic deformation of weld interface is the key factor to obtain good joint. Firstly, appropriate welding parameters can promote the removal of oxide on the surface of aluminum and copper. Broken oxides are removed by the flowing metal from the bonding zone and then transferred to the edge of the welding interface. Secondly, it is conducive to metal contact, which is a necessary condition for ultrasonic welding. Atomic forces can take effect until the interface is close enough. Thirdly, the plastic deformation of the interface is the key to produce the excellent density of the weld. However, in the welding process, there are a lot of microdefects on the contact surface of sheet metal. The method of filling these defects is reasonable plastic deformation and extrusion flow filling to form more effective contact area.

The metal-atom diffusion degree is a key indicator that helps judge the performance of welded joints. The more it diffuses, the closer the aluminum/copper welding and the better performance will be. Convection does not occur in solids, and diffusion is the only mode of material transport. The essence of this process is that thermally activated atoms migrate through their thermal vibrations to overcome their constraints. Pure Al and $\mathrm{Cu}$ belong to face-centered cubic lattice and their lattice type is same. The atomic radius of $\mathrm{Cu}$ is $1.28 \mathrm{~A}$ and the lattice constant is 3.597A. The atomic radius of $\mathrm{Al}$ is $1.43 \mathrm{~A}$ and the lattice constant is $4.059 \mathrm{~A}$. Atoms form a diffusion layer by entering the crystal lattice of the opposite element, so pure $\mathrm{Al}$ and $\mathrm{Cu}$ can form solid without forming intermetallic compounds and they can achieve a good connection.

In this study, EDS analysis on the thickness and variation of the interface diffusion layer of the $\mathrm{Al} / \mathrm{Cu}$ ultrasonic welded joint is carried out. The results are shown in Fig. 3-7. Atomic diffusion of $\mathrm{Al}$ and $\mathrm{Cu}$ occurs near the interface. EDS line scanning results of $\mathrm{Cu} / \mathrm{Al}$ sample 3, $\mathrm{Al} / \mathrm{Cu}$ sample 1 and sample 3 show that the atomic content of $\mathrm{Al}$ and $\mathrm{Cu}$ in the atomic diffusion layer transits continuously and smoothly from 0 to $100 \%$. 
The results confirm that no stable intermetallic compound has been formed at the interface between $\mathrm{Al}$ and $\mathrm{Cu}$. Fig. 3-7a Cu/Al sample 3 has an atomic diffusion layer of $1 \mu \mathrm{m}$, Fig. 3-7b Al/Cu sample 1 has an atomic diffusion layer of $1.5 \mu \mathrm{m}$, and Fig. 3-7c $\mathrm{Al} / \mathrm{Cu}$ sample 3 has an atomic diffusion layer of $2 \mu \mathrm{m}$.

Fig. 3-8 shows that the thickness of the atomic diffusion layer increases gradually to $2 \mu \mathrm{m}$ with the change of process parameters. The performance of aluminum-copper lap joint is the best under the welding parameters of $\mathrm{Al} / \mathrm{Cu}$ sample 3 .
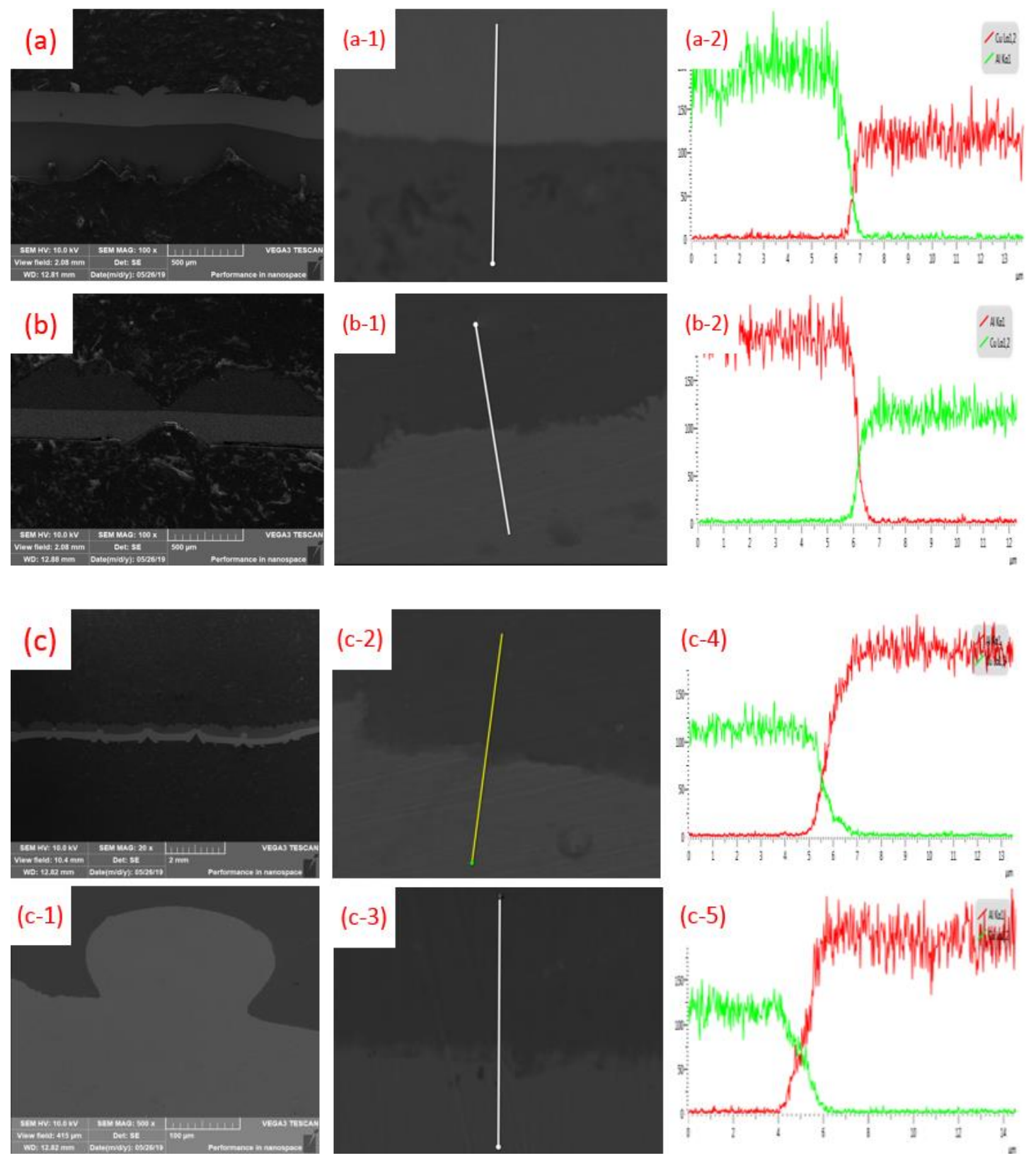

Fig. 3-7 Atomic Diffusion in Samples with Different Welding Parameters 


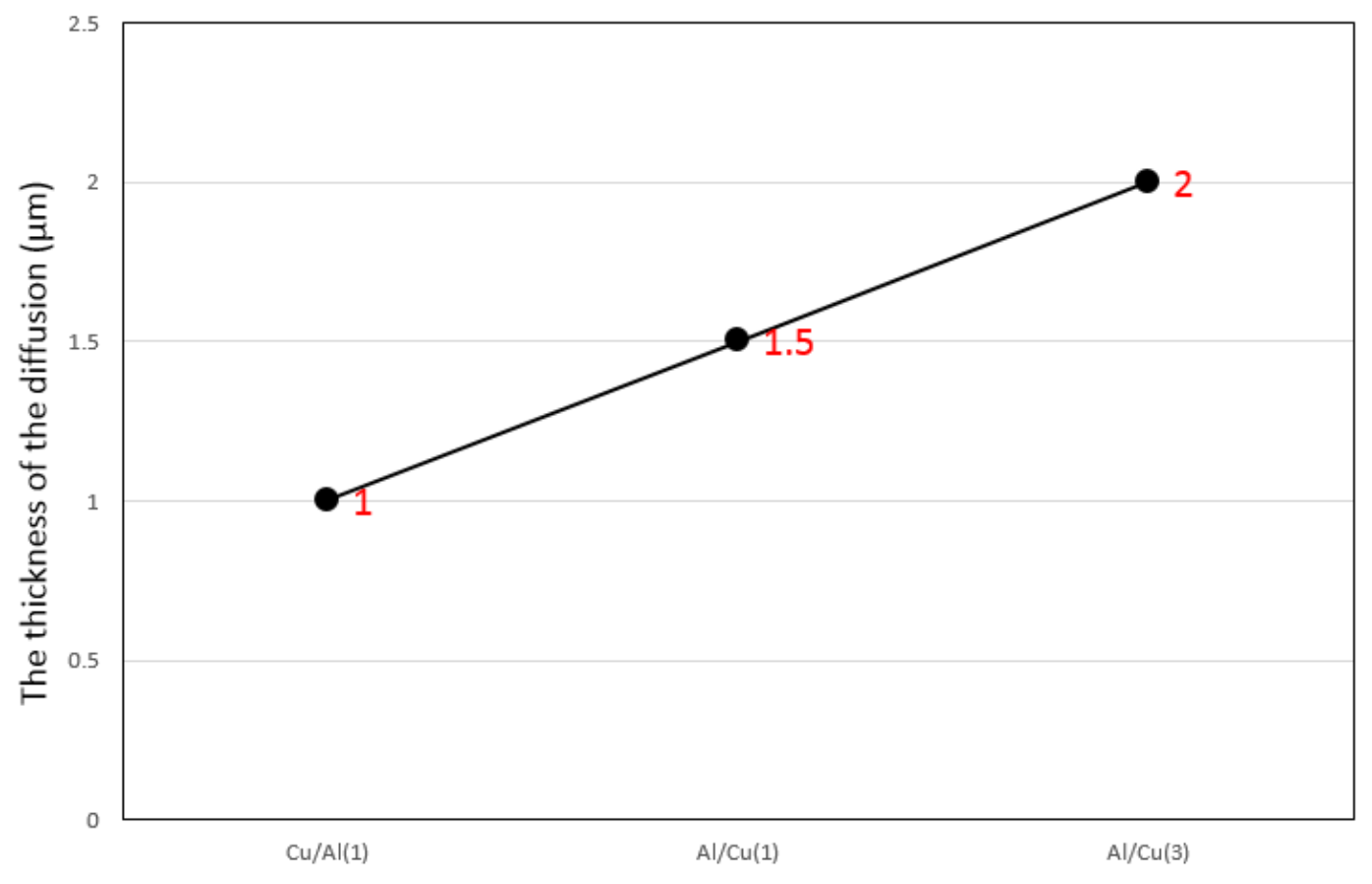

Fig. 3-8 Atomic Diffusion Layer Thickness of Samples with Different Welding Parameters

There are microcosmic defects in the material itself. In large plastic deformation, a large number of geometric dislocations will occur around the voids because the voids do not match the deformation of the matrix. The grain boundary dislocation slips at the small hole, and the hardness of the plug increases with the accumulation of dislocations. Work hardening effect is produced in the plastic deformation region of the material.The following figure shows the load-depth curve of aluminum-copper sample 3 . The curve has obvious loading and unloading processes. The elastic and plastic deformations occur successively as the load on the surface of aluminum-copper increases uniformly from $0 \mathrm{mN}$ to $10 \mathrm{mN}$. The combined action of two different deformations results in the non-linear change of load and indentation depth. When unloading drops to 0, elastic deformation gradually recovers while plastic deformation remains, resulting in indentation. The nanoindentation at the interface joint of aluminum-copper sample 3 is studied as shown in Fig. 3-9 below. The hardness of aluminum-copper near the weld is the highest. Fig. 3-9c shows that the hardness of 1 to 4 increases gradually. This is because the diffusion of elements reduces the vacancy between the crystals and the plastic deformation reduces the material defects, so that the hardness near the weld copper side improves. Fig. 3-9 f shows that the hardness of 1-6 decreases gradually. This is due to the existence of interstitial voids and material defects at the distance of 1 to 6 from the weld. When the welding pressure is 40Psi, the welding energy is $450 \mathrm{~J}$ and the welding amplitude is $37 \mathrm{~m}$, the welding interface is completely connected and there is no defect in the joint. There is a $2 \mu \mathrm{m}$ atomic diffusion layer at the junction, which makes the lattice structure denser and strengthens the strength of the junction; therefore, the $\mathrm{Al} / \mathrm{Cu}$ heterogeneous metals are strengthened in both macroscopic and microscopic aspects and obtain the optimal performance. 

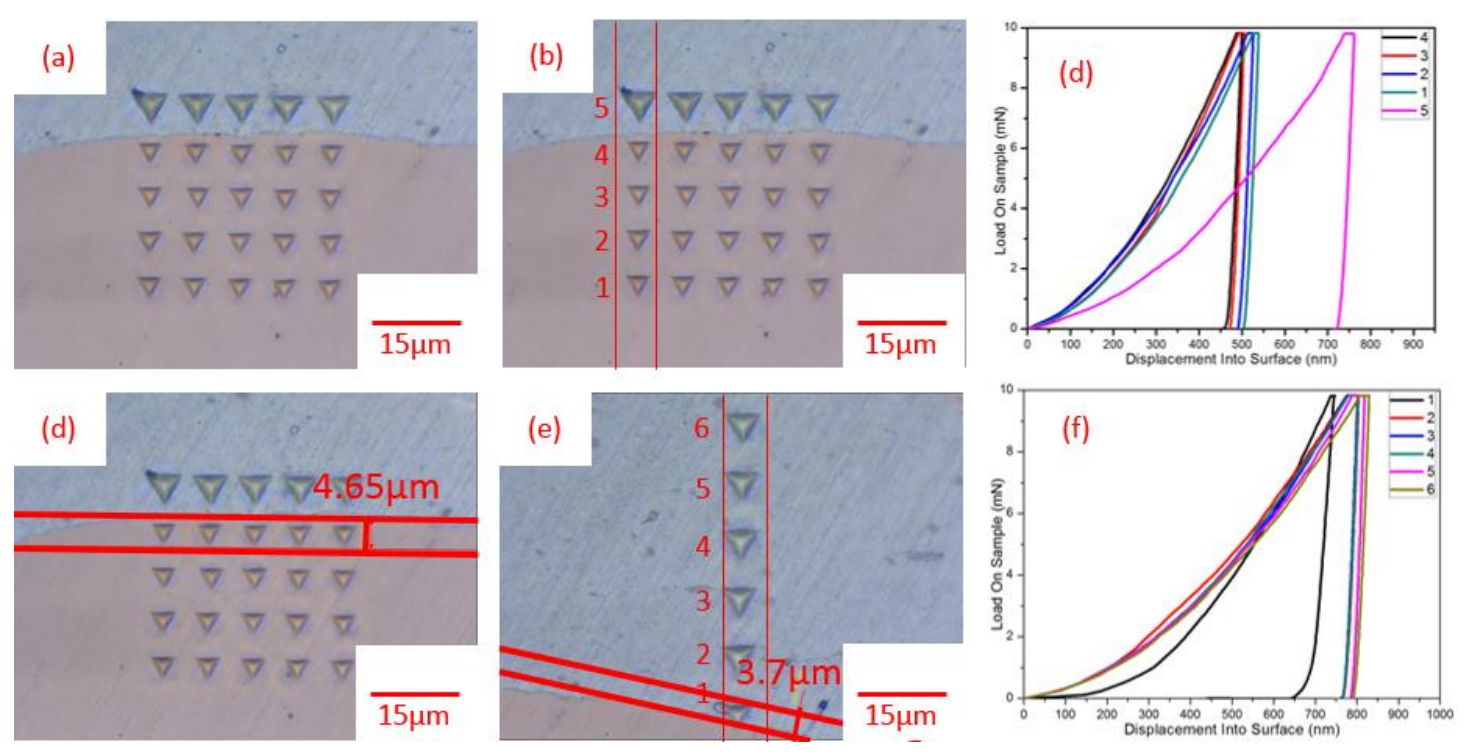

Fig. 3-9 Al/Cu sample 3 Nanoindentation

\subsection{Fracture morphology}

\section{Conclusions}

In this study, the test on ultrasound spot welding of $0.2 \mathrm{~mm} 1060 \mathrm{Al}$ alloy and $0.2 \mathrm{~mm}$ $\mathrm{T} 2 \mathrm{Cu}$ dissimilar materials is conducted through the method of aluminum on the top and copper on the bottom $(\mathrm{Al} / \mathrm{Cu})$ and copper on the top and aluminum on the bottom $(\mathrm{Cu} / \mathrm{Al})$. The effects of welding parameters (welding pressure, welding amplitude and welding energy) on the quality of joint are studied. The effects of welding parameters of two lapping methods on the hardness and microstructures of ultrasonic welded joints are discussed; and the forming process of aluminum-copper dissimilar metal joints is analyzed. The main conclusions are as follows:

(1) In the absence of bonding or virtual welding between the welding head and the workpiece, the performance of the joints $\mathrm{Al} / \mathrm{Cu}$ is better than that of $\mathrm{Cu} / \mathrm{Al}$.

(2) Welding pressure, welding energy and welding amplitude have great influence on the quality of aluminum-copper dissimilar joints. Too much or too little welding energy

(3) will lead to a lower quality of the joint. The optimum welding parameters are welding pressure 40Psi, welding energy $450 \mathrm{~J}$ and welding amplitude $37 \mu \mathrm{m}$.

(4) In the process of ultrasonic welding, the plastic deformation of aluminum and copper occurs dramatically. With seriously internal plastic deformation. The plastic deformation of mechanical occlusion will occur between the interfaces. When the optimum process parameters are welding pressure 40 Psi, welding energy 450J and 
welding amplitude $37 \mathrm{um}$, the weld interface is fully bonding and there is no defectcovered mechanical occlusion at the joint.

(5) Under microhardness, the hardness near the metal atom diffusion layer on both sides of aluminum-copper is stronger than that at the non-diffusion area.

(6) The fracture of aluminum-copper welding belongs to brittle fracture, and the bonding strength of the center interface is higher than that of the edge interface.

(7) In the experiment, the interface of aluminum-copper joint is bonded by metal and strengthened by mechanical occlusion and metal atom diffusion. There are no intermetallic compounds.

\section{Acknowledgements}

This research was supported by Natural Science Foundation of China (51605276, 51905333), Shanghai Sailing Program (19YF1418100), Shanghai Science and Technology Committee Innovation Grant (17JC1400600, 17JC1400601, 19511106400, 19511106402), Karamay Science and Technology Major Project (2018ZD002B), Aid for Xinjiang Science and Technology Project (2019E0235), Shanghai Local Colleges and Universities Capacity Building Special Plan Project (19030501300). 


\section{References}

[1] Liu, J., Pu, J., \& Jiang, Z. (2017). Promoting Strategy of New Energy Vehicles Collaborative Innovation: The Case Study of Yutong. Procedia Engineering. https://doi.org/10.1016/j.proeng.2017.01.253

[2] Kim, D. H., Kim, M. J., \& Lee, B. K. (2017). An integrated battery charger with high power density and efficiency for electric vehicles. IEEE Transactions on Power Electronics. https://doi.org/10.1109/TPEL.2016.2604404

[3] Handbuch Lithium-Ionen-Batterien. (2013). In Handbuch Lithium-Ionen-Batterien. https://doi.org/10.1007/978-3-642-30653-2

[4] Bandhauer, T. M., Garimella, S., \& Fuller, T. F. (2011). A critical review of thermal issues in lithium-ion batteries. Journal of the Electrochemical Society. https://doi.org/10.1149/1.3515880

[5] Wang, X., Gu, C., Zheng, Y., Shen, Z., \& Liu, H. (2014). Laser shock welding of aluminum/aluminum and aluminum/copper plates. Materials and Design. https://doi.org/10.1016/j.matdes.2013.10.091

[6] Zubiri, F., del Mar Petite, M., Ochoa, J., \& Sebastian, M. S. (2016). Welding Optimization of Dissimilar Copper-Aluminum Thin Sheets with High Brightness Lasers. In Cracking Phenomena in Welds IV. https://doi.org/10.1007/978-3-319-28434-7_11

[7] Solchenbach, T., \& Plapper, P. (2013). Mechanical characteristics of laser braze-welded aluminium-copper connections. Optics and Laser Technology. https://doi.org/10.1016/j.optlastec.2013.06.003

[8] Hartel, U., Ilin, A., Bantel, C., Gibmeier, J., \& Michailov, V. (2016). Finite element modeling for the structural analysis of $\mathrm{Al}-\mathrm{Cu}$ laser beam welding. Physics Procedia. https://doi.org/10.1016/j.phpro.2016.08.147

[9]Schmidt, P. A., Schweier, M., \& Zaeh, M. F. (2012). Joining of lithium-ion batteries using laser beam welding: Electrical losses of welded aluminum and copper joints. ICALEO 2012 - 31st International Congress on Applications of Lasers and Electro-Optics. https://doi.org/10.2351/1.5062563

[10] Abbasi, M. , A. K. Taheri, and M. T. Salehi . "Growth rate of intermetallic compounds in Al/Cu bimetal produced by cold roll welding process." Journal of Alloys and Compounds 319.12(2001):0-241.

[11]Solchenbach, T., Plapper, P., \& Cai, W. (2014). Electrical performance of laser braze-welded aluminum-copper interconnects. Journal of Manufacturing Processes. https://doi.org/10.1016/j.jmapro.2013.12.002

[12]Hetrick, E. T., Baer, J. R., Zhu, W., Reatherford, L. V., Grima, A. J., Scholl, D. J., .. Ward, S. M. (2009). Ultrasonic metal welding process robustness in aluminum automotive body construction applications. Welding Journal. 
[13] Chen, Y. C., Bakavos, D., Gholinia, A., \& Prangnell, P. B. (2012). HAZ development and accelerated post-weld natural ageing in ultrasonic spot welding aluminium 6111-T4 automotive sheet. Acta Materialia. https://doi.org/10.1016/j.actamat.2012.01.047

[14] Shakil, M., Tariq, N. H., Ahmad, M., Choudhary, M. A., Akhter, J. I., \& Babu, S. S. (2014). Effect of ultrasonic welding parameters on microstructure and mechanical properties of dissimilar joints. Materials and Design. https://doi.org/10.1016/j.matdes.2013.09.074

[15] Hu, S.J., Senkara, J., Zhang, H., 1996. Performance characteristics of resistance spot welds in the automotive industry: A structural point of view. Proceedings of

IBEC'96 Body and Engineering, 91-98.

[16]Lee, S. H., \& Lee, J. (2013). Aerodynamic analysis and multi-objective optimization of wings in ground effect. Ocean Engineering. https://doi.org/10.1016/j.oceaneng.2013.04.018

[17]Liedtke, A., \& Elssner, G. (1999). Untersuchung von diffusionsverschweissten Cu/ $\alpha$-Al2O3Verbunden am Auflicht- und Rasterelektronenmikroskop. Praktische Metallographie/Practical Metallography.

[18] Fujii, H. T., Goto, Y., Sato, Y. S., \& Kokawa, H. (2016). Microstructure and lap shear strength of the weld interface in ultrasonic welding of $\mathrm{Al}$ alloy to stainless steel. Scripta Materialia. https://doi.org/10.1016/j.scriptamat.2016.02.004 